\title{
Experimental and Numerical Investigation on Air Flow and Temperature Distribution under different Geometries of Displacement Ventilation Devices in an Office Room
}

\author{
Muna Hameed Al Tuarihi \\ Mechanical Engineering department, Iraq \\ College of Engineering \\ University of Kufa
}

\author{
Ala'a Abbas Mahdi \\ Mechanical Engineering department, Iraq \\ College of Engineering \\ University of Babylon
}

\begin{abstract}
Room air distributions are intended to achieve the required thermal comfort and ventilation for space occupants and processes. The type of air supply diffuser, the type and situation of return grille in the room may affect in the room air distribution and human thermal comfort. In this study three types of air supply diffusers (three direction-square air supply diffuser, one direction-square air supply diffuser and semi-circle air supply diffuser) were used separately as a supply air terminal with one return air grille.

The control on the behavior of the air distribution in the enclosed space was very complex. One approach to achieve an optimal control was done by modeling the distribution of air. The tested room was built and meshes by Ansys Fluent14Users guide program. Realizable, $\mathrm{k}-\varepsilon$ turbulence model was evaluated in predicting the airflow pattern and thermal behavior of DV devices in an office room according to different geometries of displacement ventilation devices. A comparison between both results obtained from experimental work and data of numerical analysis indicated a good agreement between these results due to Iraqi cooling code and ASHRAE standards and according to values of Air Diffusion Performance Index (ADPI) and Effectiveness temperature $\left(\varepsilon_{\mathrm{t}}\right)$. The three direction-square diffuser was the best type compared with the others two types since it gives $(66.76 \%)$ and(1.82) respectively, and the semi-circle type gives (62.3) \% and (1.55) respectively .Also the measured of relative humidity gives approximated converged values between all the three devices.
\end{abstract}

\section{Keywords}

Displacement ventilation ;Air supply diffuser; return air grille; CFD; air distribution; relative humidity.

\section{INTRODUCTION}

H.B.Awbi,2002,[1], examined relation between neutral height of air distribution and ventilating load in a room with displacement ventilation. A neutral height measurement with the existence of heated models as heat sources was carried out to an environmental chamber supplied with displacement ventilation system. Also, three types of diffuser were used and these types are: a flat diffuser, a semi-circular diffuser and floor swirl diffuser. Different heating loads varying from (104 to 502) W was used. The plume theory was used to calculate of the neutral height. A comparison between both results obtained from experimental work and data of numerical analysis indicated a good agreement between these results.

Karimipanah, 2007,[2], studied both the consumption of energy and the performance evaluation of air supply systems for a room when ventilated by high and low-level air supply grills based on the airflow rate to assess energy performance, which is depend on fan power consumption by reaching the same environmental quality performance for each case. Four ventilation techniques were used: wall displacement, confluent jets, impinging jet ventilation and a high level mixing ventilation. The ventilation performance of these systems was examined by reaching the same Air Distribution Index (ADI) for different cases. Ting Yao, 2014,[3], aimed to study the influence of air terminal layouts on the stratum ventilation performance. Four different air terminal layouts were studied. A CFD model validated by experimental data was applied. Similar ventilation performance is found with exhausts placed at middle or low level of the wall opposite to the supply wall. In the case with exhausted located at ceiling level, lower temperature distribution of occupied zone was observed, which leads to relative low EDTs. However, with this arrangement, more fresh air could be supplied to the occupants' breathing zone. Compared with other cases, performance of case with exhausts placed at the supply wall is better. Relative uniform temperature and EDTs distribution, acceptable thermal comfort and fine air quality could be reached. It also helps to save system installation space. Thus, it is a good method to meet stratum ventilation design performance requirement. Yukihiro,2005,[4], investigated the airflow in an office with a displacement ventilation system making use of three dimensional CFD analyses. This study was done numerically for an office room with dimensions $(6 \mathrm{~m} \times 6 \mathrm{~m} \times 3 \mathrm{~m})$. Air outlets grills were placed at the bottom of the wall while air inlet diffusers were placed at the top of the opposite wall. A cubic model of heat source was used with dimensions ( $1 \mathrm{~m} \times 1$ $\mathrm{m} \times 1 \mathrm{~m})$. Two cases were reported for the location of the internal heat sources, a heat source was installed at room center and four heat sources were placed separated from each other in the office room. The finite volume method and the low Re .No. $\mathrm{k}-\varepsilon$ turbulence model were used to get numerical solution of governing differential equations. The stratification profiles in the room affected strongly by velocity of supplied air. This indicates that the variable air volume (VAV) systems are applicable for controlling air temperature in room when using a displacement ventilation system.

Kisup Lee. 2009,[5], compared the airflow, air temperature, and contaminant or air distribution effectiveness distributions in indoor spaces between the TDV and UFAD systems using both experimental and numerical approaches. The experimental approach gave the most realistic data to describe the ventilation performances of the systems but had low data resolution. The numerical simulations, well calibrated by the experiment, can provide detailed information on the ventilation performance and can easily show different sizes of indoor 
spaces, such as an office, a classroom, and a workshop. The results obtained with the CFD program are agreed well with the data from experiments.

The present study will focus on experimental and numerical investigation on airflow and thermal behavior under different geometries of displacement ventilation devices in an office room.

\section{EXPERIMENTAL SET-UP}

Three types of supply air diffusers at different ambient conditions were included in this work. All experiments in this work were done at laboratory of Mechanical Engineering / College of Engineering/ University of Kufa.Design conditions used in this paper depends on Iraqi cooling code for Najaf city. A steady-state working conditions were assumed in both experimental and numerical analysis.

\subsection{The Office Room Design:}

Full-scale office room experiments was adopted to study temperature distribution, velocity magnitude and relative humidity using DV system under Iraqi climate by using three types of supply air diffusers. The test room dimensions are (length $\mathrm{x}$ width $\mathrm{x}$ height): $(4 \times 3 \times 3.2) \mathrm{m}$, which is the same to a typical single person office room, included one window located at south side and one door at west side as shown in Figs $1 \& 2$.

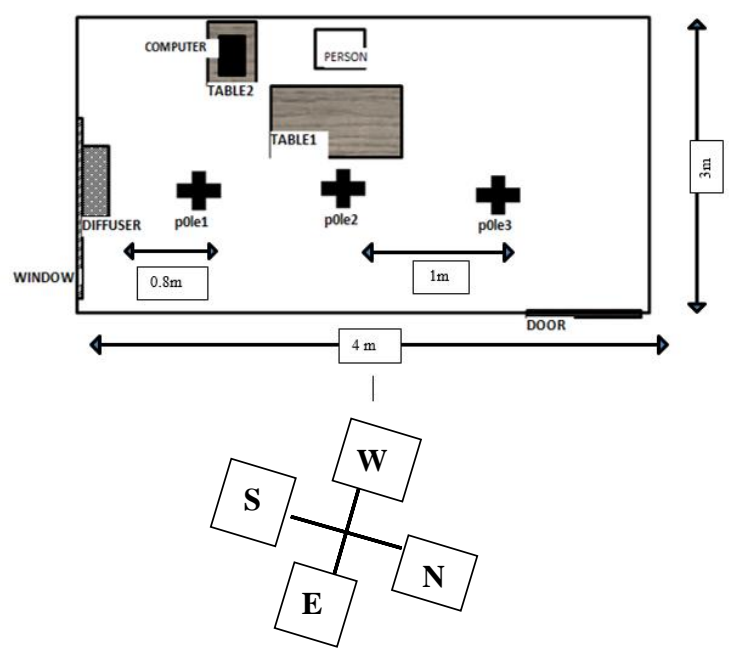

Fig.1 Top view of the test room

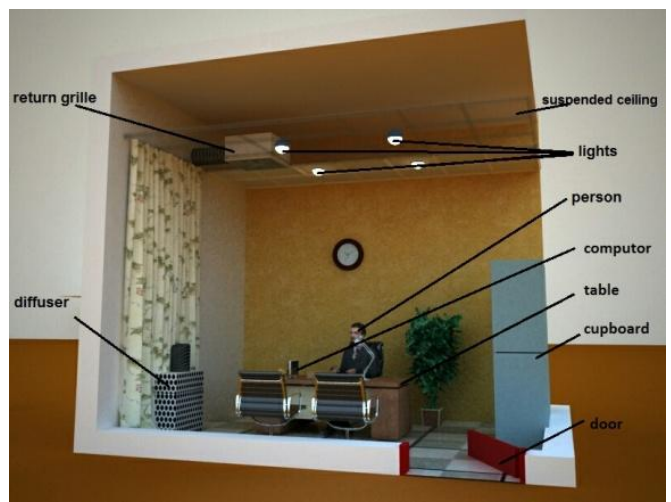

Fig. 2 Schematic diagram of tested office room

The different objects which located at tested room and adopted during experiment part were three types of heat sources used in tested room and commercial air-conditioner was used to deliver the cooled air to indoor space of the room by fitting a short insulated duct at the supply opening of the unit. The basic configuration requirements for the test room have been indicated and they are summarized in table 1 .

To find ventilation rate and supply air temperature for displacement ventilation applications. The required air flow rate for cooling load,[6] is:

$\left.\mathrm{Q}=\left(0.295 \mathrm{q} \_\mathrm{oe}+0.132 \mathrm{q} \_1+0.185 \mathrm{q} \_\mathrm{ex}\right) /(\rho \mathrm{cp} \llbracket \Delta \mathrm{t}) \rrbracket \mathrm{hf}\right) \quad 1$

Where,

$\mathrm{Q}=$ required air flow rate to meet the sensible cooling load in system, $[1 / \mathrm{s}]$

$\Delta \mathrm{t}_{\mathrm{hf}}=$ temperature difference from head to foot level, $\left[{ }^{\circ} \mathrm{C}\right]$.

Equation 2 was used to predict temperature of supplied air $\left(\mathrm{T}_{\mathrm{s}}\right)$ during the experiments, [6]

Table 1 Room configuration, (non- isothermal condition)

\begin{tabular}{|l|c|c|c|c|}
\hline \multirow{2}{*}{ Item } & \multicolumn{2}{c|}{ Location } & \multirow{2}{*}{ Heat[7] } \\
\cline { 2 - 5 } & $\boldsymbol{X}$ & $\boldsymbol{Y}$ & $\boldsymbol{Z}$ & \\
\hline Room & & & & $\boldsymbol{W}$ \\
\hline Table1 & 0.8 & 1.5 & 0.7 & 0 \\
\hline Table2 & 0.1 & 1 & 0.7 & 0 \\
\hline Computer1 & 0.2 & 1.1 & 0.9 & 45 \\
\hline Single-person & 2.5 & 0 & 0.4 & 75 \\
\hline Light1 & 0.8 & 0.8 & 3.2 & 1000 \\
\hline Light2 & 2.4 & 0.8 & 3.2 & 1000 \\
\hline Light3 & 0.8 & 3.2 & 3.2 & 1000 \\
\hline Light4 & 2.4 & 3.2 & 3.2 & 1000 \\
\hline $\begin{array}{l}\text { Cupboard with } \\
\text { two doors }\end{array}$ & 0.85 & 3.5 & 0 & 0 \\
\hline Window & 0.18 & 1 & 0 & 0 \\
\hline Door & 0.1 & 0.1 & 0 & 0 \\
\hline
\end{tabular}

$$
\text { T_s=t_sp- }(\Delta t) \rrbracket \text { hf- }\left(A \_f * q \_t\right) /\left(0.584 * \mathrm{Q}^{\wedge} 2+1.208 * \mathrm{~A} * \mathrm{Q}\right)
$$

According to Iraqi cooling code and ASHRAE standard, the heat flux from persons and temperature difference from head to foot level can be selected:

\begin{tabular}{|c|c|}
\hline$q_{\text {person }}$ & $\Delta \boldsymbol{T}_{h f}($ For all cases $)$ \\
\hline $\mathbf{7 5} \mathrm{W}$ & $3^{\circ} \mathrm{C}$ \\
\hline
\end{tabular}

The air change per hour $(\mathrm{ACH})$ was determined by equation 3 , [8].

$$
\mathrm{ACH}=\left(\mathrm{Q} / \mathrm{V} \_ \text {Room }\right) * 3600
$$

presents the value of air flow rate $\left(\mathrm{Q}_{\mathrm{s}}\right)$, supply air temperature and air change per hour (ACH) for all cases.

Table 2 calculated values of air flow $\operatorname{rate}\left(Q_{s}\right)$, supply air temperature $\left(\mathrm{T}_{\mathrm{s}}\right)$ and air change per hour $(\mathrm{ACH})$.

\begin{tabular}{|c|c|c|}
\hline$Q_{s}(l / s)$ & $\boldsymbol{T}_{\boldsymbol{s}}\left({ }^{\boldsymbol{o}} \boldsymbol{c}\right)$ & $\boldsymbol{A C H}$ \\
\hline $\mathbf{1 2 2}$ & 20 & 11.25 \\
\hline
\end{tabular}




\subsection{Supply System Design:}

\subsubsection{Supply grill (diffuser):}

For the three types used in this study, all models used are wall mounted displacement diffusers. The external body for the three types were manufactured in local markets after the appropriate design for each type of adoption and they made from high gauge steel, flat perforated faces that are held by high strength extruded aluminum frames as shown in Fig.3. The perforated faces ensure equalized, airflow across the face of the diffuser and provide low velocity air into the room. These diffusers are typically installed along a sidewall, against pillar, or integrated onto features such as bookcases.

The dimensions for each type of supply air units are shown in table 3.The characteristics and positions of supply air units for each type, which used in this study are listed in table 4.

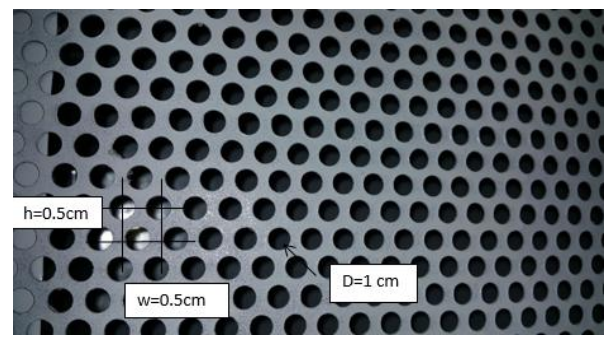

Fig. 3 Dimensions of the holes at face of diffuser

Table 3 Area and height of the three different low velocity diffusers.

\begin{tabular}{|c|c|c|c|}
\hline Diffuser & Type-I & Type-II & Type-III \\
\hline $\begin{array}{l}\text { Area } \\
\quad m^{2}\end{array}$ & 0.485 & 0.48 & $2 * 0.261$ \\
\hline $\begin{array}{r}\text { Height } \\
\text { m }\end{array}$ & 0.5 & 0.58 & 0.58 \\
\hline
\end{tabular}

Table 4 Location of the three different low velocity diffusers used in the test room

\begin{tabular}{|c|c|c|c|c|c|}
\hline & \multirow{2}{*}{\multicolumn{2}{|c|}{ Item }} & \multicolumn{3}{|c|}{ Location ( $m$ ) } \\
\hline & & & $X$ & $Y$ & $Z$ \\
\hline \multicolumn{3}{|l|}{ Room } & - & - & - \\
\hline \multirow{4}{*}{ Diffuser } & \multicolumn{2}{|l|}{ Type-I } & 1.25 & 0 & 0 \\
\hline & \multicolumn{2}{|l|}{ Туре-II } & 1.25 & 0 & 0 \\
\hline & \multirow{2}{*}{ Type-III } & right & \multirow{2}{*}{1.25} & \multirow{2}{*}{0} & \multirow{2}{*}{0} \\
\hline & & left & & & \\
\hline return grille & \multicolumn{2}{|c|}{ square $(0.6 * 0.6)$} & 1.25 & 1.2 & 3.2 \\
\hline
\end{tabular}

\subsubsection{Information about three direction-square diffuser:}

This type of displacement diffusers is illustrated in Fig. 4. This type of diffusers can be freely stood to supplies air equally across its perforated face with minimum induced turbulence caused in room air zone. The cool supply air flows down to the floor level and gradually fills the occupied space. The low noise levels of these diffusers air supplying with the $3 \mathrm{df}$ makes it appropriate for use in places that needs quite atmosphere like offices, restaurants, theaters, hotels, schools, etc.

\subsubsection{Information about semi-circle diffuser:}

This type of diffusers shown in Fig. 5 supplied air with low turbulence in an $180^{\circ}$ direction pattern. Also these diffusers supplies air equally across its perforated face. The supplied cooled air dropped at floor level and slowly floats into the occupied zone. The curved geometry of these diffusers makes it easily fit with any decoration type giving the space a specific touch beauty. The low noise levels of these diffusers air supplying with the $3 \mathrm{df}$ makes it appropriate for use in places that needs quite atmosphere like offices, restaurants, theaters, hotels, schools, etc.

\subsubsection{Information about one direction diffuser:}

This type of diffusers shown in Fig. 6 supplied air with low velocity normally an equally on its perforated face to room in floor level. The supplied cooled air flowed at floor level and gently spreads into the occupied zone. This type usually installed at corners of a $90^{\circ}$ and provides a beautiful scene in room corner as shown in Fig.7. The low noise levels of these diffusers air supplying with the one direction makes it appropriate for use in places that needs quite atmosphere like offices, restaurants, theaters, hotels, schools, etc.

\subsection{Experimental Procedures:}

The experiment work have done in three steps. Each step included changed the type of DV diffuser. The experiments were done at period from May 2016 to July 2016 from 9Am to $2 \mathrm{Pm}$ per day to reach steady state conditions. It should be mentioned that during the measurements, the change in ambient conditions was ignored when the measurement of the same type of ventilation is taken in order to enable the researcher to make the comparison between one type of ventilation system under the same conditions. Tables 5 to 7 show the results of all cases for each pole from the experimental study.

Table 5 Temperature $\left({ }^{\circ} \mathrm{C}\right)$ obtained by adopting DV System

\begin{tabular}{|c|c|c|c|c|c|c|}
\hline $\begin{array}{c}\text { Type of } \\
\text { diffuser }\end{array}$ & $\begin{array}{c}\text { Height } \\
(\boldsymbol{m})\end{array}$ & $\mathbf{0 . 4}$ & $\mathbf{0 . 8}$ & $\mathbf{1 . 2}$ & $\mathbf{1 . 6}$ & $\mathbf{2}$ \\
\hline \multirow{4}{*}{ Type I } & Pole1 & 22.6 & 23.1 & 23.7 & 23.9 & 25 \\
\cline { 2 - 7 } & Pole2 & 23.25 & 23.1 & 23.9 & 24.75 & 25.45 \\
\cline { 2 - 7 } & Pole3 & 23 & 22.4 & 24.15 & 24.4 & 25.75 \\
\hline \multirow{4}{*}{ Type II } & Pole1 & 22.25 & 23.6 & 24.3 & 24.6 & 26.85 \\
\cline { 2 - 7 } & Pole2 & 22.5 & 23.4 & 24.95 & 27.2 & 26.9 \\
\cline { 2 - 7 } Type & Pole3 & 22.6 & 23 & 23.8 & 25 & 27.5 \\
\cline { 2 - 7 } III & Pole1 & 23 & 24.45 & 25.15 & 26.15 & 26.7 \\
\cline { 2 - 7 } & Pole2 & 23.15 & 24.3 & 25.05 & 25.85 & 26.45 \\
\cline { 2 - 7 } & Pole3 & 23.65 & 24.7 & 26.6 & 26.3 & 26.85 \\
\hline
\end{tabular}

Table 6 Velocity $(\mathrm{m} / \mathrm{s})$ obtained by adopting DV system.

\begin{tabular}{|c|c|c|c|}
\hline Type of diffuser & $\begin{array}{c}\text { Height } \\
(\boldsymbol{m})\end{array}$ & $\mathbf{0 . 8}$ & $\mathbf{1 . 6}$ \\
\hline \multirow{2}{*}{ Type I } & Pole1 & 0.03 & .02 \\
\cline { 2 - 4 } & Pole3 & 0.02 & .01 \\
\hline \multirow{2}{*}{ Type II } & Pole1 & 0.02 & .01 \\
\cline { 2 - 4 } & Pole2 & 0.01 & .01 \\
\hline \multirow{2}{*}{ Type III } & Pole1 & 0.02 & .01 \\
\cline { 2 - 4 } & Pole2 & 0.01 & .01 \\
\hline
\end{tabular}


Table 7 Relative humidity(\% )obtained by adopting DV

\begin{tabular}{|c|c|c|c|}
\hline Type of diffuser & $\begin{array}{c}\text { Height } \\
(\boldsymbol{m})\end{array}$ & $\mathbf{0 . 8}$ & $\mathbf{1 . 6}$ \\
\hline \multirow{3}{*}{ Type I } & Pole1 & 33.5 & 33.9 \\
\cline { 2 - 4 } & Pole2 & 35.6 & 35.8 \\
\cline { 2 - 4 } & Pole3 & 35.4 & 33.4 \\
\hline \multirow{3}{*}{ Type II } & Pole1 & 28.3 & 29 \\
\cline { 2 - 4 } & Pole2 & 17.5 & 17.2 \\
\cline { 2 - 4 } & Pole3 & 28.9 & 28.5 \\
\hline \multirow{3}{*}{ Type III } & Pole1 & 29.4 & 30.4 \\
\cline { 2 - 4 } & Pole2 & 15.4 & 16 \\
\cline { 2 - 4 } & Pole3 & 30 & 29.9 \\
\hline
\end{tabular}

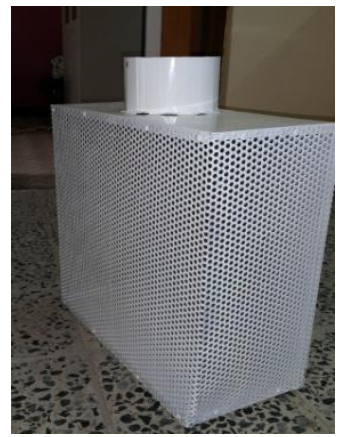

a. Photograph for manufactured DV

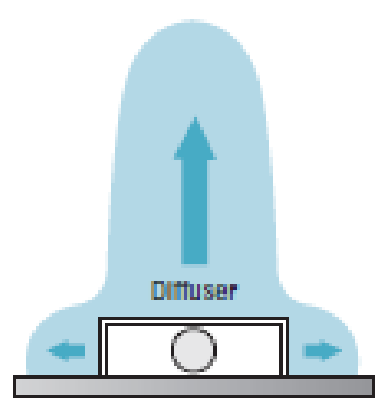

b. Schematic for DV (Top view)
Fig.4Three direction air supply diffuser(Type I)

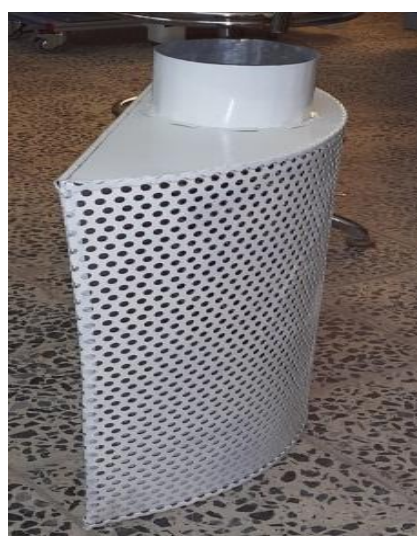

a. Photograph for manufactured DV(Type-II)

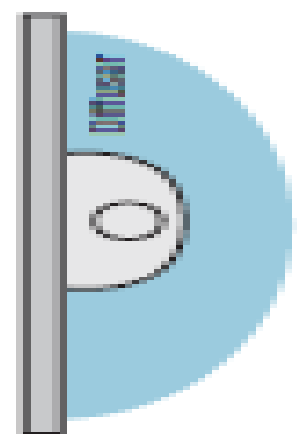

b. Schematic for Semicircular DV(Top view) [9]
Fig. 5 Semicircular air supply diffuser(type II)

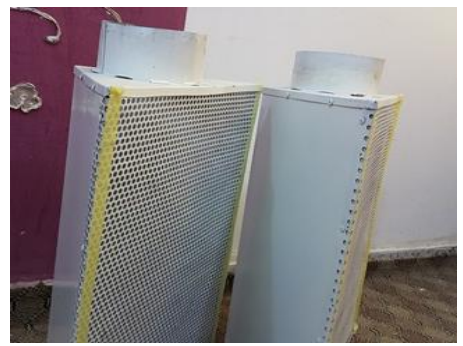

a. Photograph for manufactured diffusers

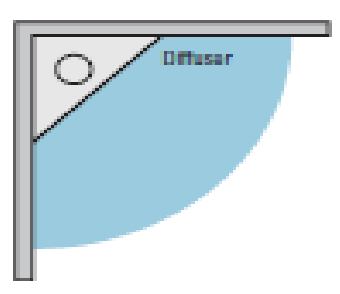

b. One direction DV
Fig.6 One direction air supply diffuser(type III)

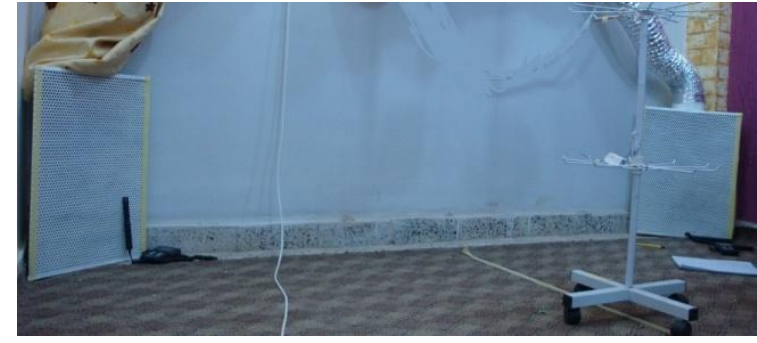

Fig.7 Photograph for supply diffuser type-III illustrated the location at test room

\section{MATHEMATICAL FORMULATION AND NUMERICAL METHODS \\ 3.1 Mathematical Formulation \\ - Conservation of mass:}

Conservation of mass is given by the following equation, [10].

$\partial / \partial x(\rho u)+\partial / \partial y(\rho v)+\partial / \partial z(\rho w)=0$ 4

- Conservation of momentum (Navier-Stokes Equations): The resultant forces effecting a differential control volume can be determined by applying momentum conservation law in each coordinate direction to get three force components in the $x, y$ and $z$ directions.

These components are given in form of differential equations below:

x-direction (U-momentum):

$\partial / \partial \mathrm{x}(\rho \mathrm{u})+\partial / \partial \mathrm{y}(\rho \mathrm{vu})+\partial / \partial \mathrm{z}(\rho \mathrm{w})=-\partial \mathrm{p} / \partial \mathrm{x}+\partial / \partial \mathrm{x}(\mu \partial \mathrm{u} / \partial \mathrm{x})+\partial / \partial \mathrm{y}$ $(\mu \partial \mathrm{u} / \partial \mathrm{y})+\partial / \partial \mathrm{z}(\mu \partial \mathrm{u} / \partial \mathrm{z})+1 / 3 \partial / \partial \mathrm{x}[\mu(\partial \mathrm{u} / \partial \mathrm{x}+\partial \mathrm{v} / \partial \mathrm{y}+\partial \mathrm{w} / \partial \mathrm{z})]+\partial / \partial \mathrm{x}$ $\left(-\rho^{-}\left(u^{\wedge^{\prime}} u^{\wedge^{\prime}}\right)\right)+\partial / \partial y\left(-\rho^{-}\left(u^{\wedge^{\prime}} v^{\wedge^{\prime}}\right)\right)+\partial / \partial z\left(-\rho^{-}\left(u^{\wedge^{\prime}} \mathrm{w}^{\wedge^{\prime}}\right)\right)+\rho g \_x$

y-direction (V-momentum):

$\partial / \partial \mathrm{x}(\rho \mathrm{vv})+\partial / \partial \mathrm{y} \quad(\rho \mathrm{vv})+\partial / \partial \mathrm{z} \quad(\rho \mathrm{vw})=-\partial \mathrm{p} / \partial \mathrm{y}+\partial / \partial \mathrm{x} \quad(\mu$ $\partial \mathrm{v} / \partial \mathrm{x})+\partial / \partial \mathrm{y}(\mu \partial \mathrm{v} / \partial \mathrm{y})+\partial / \partial \mathrm{z}(\mu \partial \mathrm{v} / \partial \mathrm{z})+1 / 3 \partial / \partial \mathrm{y}[\mu(\partial \mathrm{u} / \partial \mathrm{x}+\partial \mathrm{v} / \partial \mathrm{y}+$ $\mathrm{w} / \partial \mathrm{z})]+\partial / \partial \mathrm{x}\left(-\rho^{-}\left(\mathrm{u}^{\wedge^{\prime}} \mathrm{v}^{\wedge^{\prime}}\right)\right)+\partial / \partial \mathrm{y}\left(-\rho^{-}\left(\mathrm{v}^{\wedge^{\prime}} \mathrm{v}^{\wedge^{\prime}}\right)\right)+\partial / \partial \mathrm{z}\left(-\rho^{-}\left(\mathrm{v}^{\wedge^{\prime}}\right.\right.$ $\left.\left.\mathrm{w}^{\wedge}\right)\right)+\rho g \_\mathrm{y}$

6

\section{z-direction (W-momentum):}

$\partial / \partial \mathrm{x}(\rho \mathrm{w})+\partial / \partial \mathrm{y}(\rho \mathrm{vw})+\partial / \partial \mathrm{z}(\rho \mathrm{ww})=-\partial \mathrm{p} / \partial \mathrm{z}+\partial / \partial \mathrm{x}(\mu$ $\partial \mathrm{w} / \partial \mathrm{x})+\partial / \partial \mathrm{y}(\mu \partial \mathrm{w} / \partial \mathrm{y})+\partial / \partial \mathrm{z}(\mu \partial \mathrm{w} / \partial \mathrm{z})+1 / 3 \partial / \partial \mathrm{Z}[\mu(\partial \mathrm{u} / \partial \mathrm{x}+\partial \mathrm{v} / \partial \mathrm{y}+$ $\partial \mathrm{w} / \partial \mathrm{z})]+\partial / \partial \mathrm{x}\left(-\rho^{-}\left(\mathrm{u}^{\wedge^{\prime}} \mathrm{w}^{\wedge^{\prime}}\right)\right)+\partial / \partial \mathrm{y}\left(-\rho^{-}\left(\mathrm{v}^{\wedge^{\prime}} \mathrm{w}^{\wedge^{\prime}}\right)\right)+\partial / \partial \mathrm{z}\left(-\rho^{-}\left(\mathrm{w}^{\wedge^{\prime}}\right.\right.$ $\left.\left.\mathrm{w}^{\wedge \prime}\right)\right)+\rho g \_z$

-Conservation of thermal energy:

Applying heat energy balance on infinitesimal control volume of differential $\mathrm{d} x, \mathrm{~d} y$ and $\mathrm{d} z$ sides which demonstrate that total change in stored energy in the control volume equals the net of energy flowing inside control volume minus energy flowing outside control volume, for steady state this equation can be written as follows, [11]:

$\partial / \partial \mathrm{x}(\rho \mathrm{ut})+\partial / \partial \mathrm{y}(\rho \mathrm{vt})+\partial / \partial \mathrm{z}(\rho \mathrm{wt})=\partial / \partial \mathrm{x}(\Gamma \partial \mathrm{t} / \partial \mathrm{x})+\partial / \partial \mathrm{y}(\Gamma \partial \mathrm{t} / \partial \mathrm{y})+\partial / \partial \mathrm{z}$ $(\Gamma \partial \mathrm{t} / \partial \mathrm{z})+\partial / \partial \mathrm{x}\left(-\rho^{-}\left(\mathrm{u}^{\wedge^{\prime}} \mathrm{t}^{\wedge^{\prime}}\right)\right)+\partial / \partial \mathrm{y}\left(-\rho^{-}\left(\mathrm{v}^{\wedge^{\prime}} \mathrm{t}^{\wedge^{\prime}}\right)\right)+\partial / \partial \mathrm{z}\left(-\rho^{-}\left(\mathrm{w}^{\wedge^{\prime}} \mathrm{t}^{\wedge^{\prime}}\right.\right.$ )$)+\mathrm{S} \_\mathrm{t}$ 8

-The concentration of species equation:

Equation of species concentration is exactly the same as equation 6 Thus, equation of species concentration can be written as: 
$: \quad \partial / \partial(\rho u c)+\partial / \partial \mathrm{y}(\rho \mathrm{vc})+\partial / \partial \mathrm{z}(\rho \mathrm{wc})=\partial / \partial \mathrm{x}(\Gamma \partial \mathrm{c} / \partial \mathrm{x})+\partial / \partial \mathrm{y}(\Gamma$ $\partial \mathrm{c} / \partial \mathrm{y})+\partial / \partial \mathrm{z}(\Gamma \partial \mathrm{c} / \partial \mathrm{z})+\partial / \partial \mathrm{x}\left(-\rho^{-}\left(\mathrm{u}^{\wedge^{\prime}} \mathrm{c}^{\wedge^{\prime}}\right)\right)+\partial /(\partial \mathrm{y})\left(-\rho^{-}\left(\mathrm{v}^{\wedge^{\prime}}\right.\right.$ $\left.\left.c^{\wedge \prime}\right)\right)+\partial / \partial z\left(-\rho-\left(w^{\wedge} c^{\wedge \prime}\right)\right)+S_{-} c$

In this equation ( $c$ is the time-mean concentration and $c_{-}$is the deviation from the mean. The terms $-\rho \overline{u^{t} c^{t}},-\rho \overline{v^{t} c^{y}}$ and $-\rho \overline{w^{l} c^{l}}$ are the turbulent diffusion fluxes.

\subsection{Computational Set and Numerical Scheme}

The present study includes an office room with one heat source above a solid table and a single person as shown in Fig. 8 , the dimension illustrated for modeled room and types of displacement ventilation terminal illustrated in tables 1 and 2 .

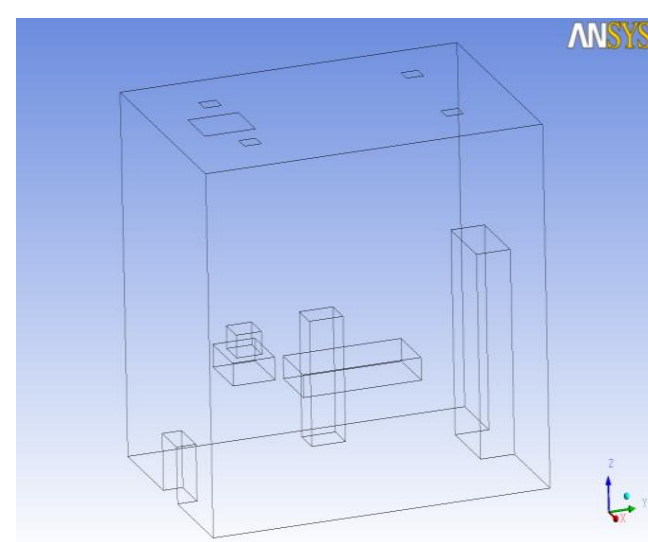

a- Type-I

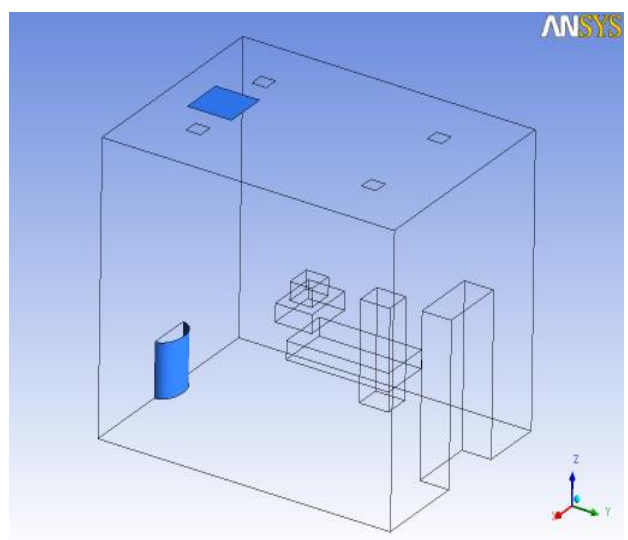

b- Type-II

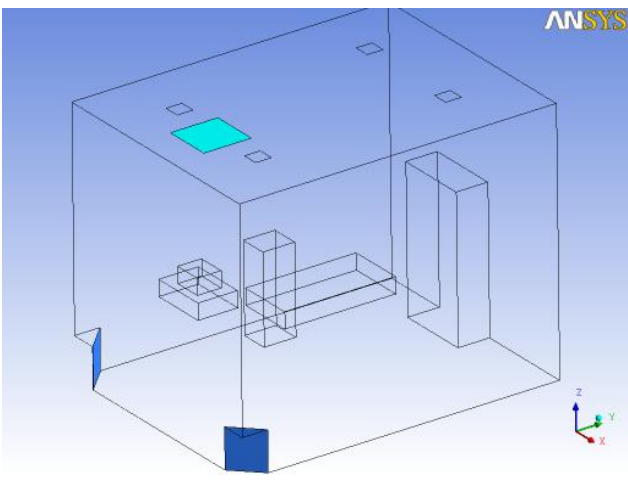

c- Type-III

Fig. 8 Configuration of tested room
The graphic results were plotted on the planes (P1, P2 and P3) as shown in Fig. 9, and the effective draft temperature(EDT) was taken in (100) points distributed along ten horizontal range at $\mathrm{Z}=1.1$ and $\mathrm{Z}=1.8$ inside the occupied zone. Also, have been performed to compare practical results with theoretical results through line (L1) shown in the same Fig 9

Most of the researchers of modeling room airflow have used the $(\mathrm{k}-\varepsilon)$ model since this model has been applied to numerous room air movement problems with good predictive accuracy to the flow. The Boussinesq hypothesis is used in the ( $\mathrm{k}-\varepsilon$ ) model, and the advantage of this approach is the relative low computational cost. In the (k- $\varepsilon$ ) model, two additional transport equations for the turbulent kinetic energy $(k)$ and turbulent dissipation rate $(\varepsilon)$ are solved, and the eddy viscosity $\left(\mu_{\mathrm{t}}\right)$ is computed as a function of $(k)$ and $(\varepsilon),[12]$. In order to make use of Boussinesq approximation in CFD modeling the density of both constituents was considered to be equal and constant.

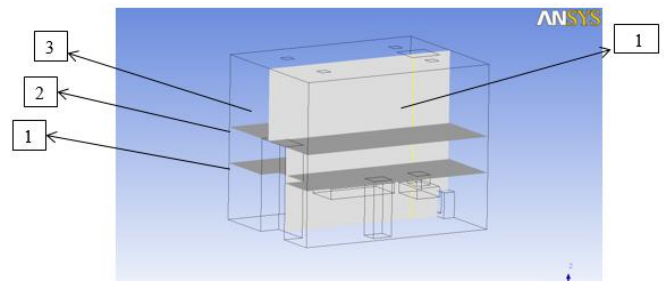

Fig. 9 Schematic of room geometry stating the plot planes for all types(Plan P1 at $\mathrm{z}=1.2 \mathrm{~m}$, Plane P2 at $\mathrm{z}=1.6 \mathrm{~m}, \mathrm{P3}$ at $\mathrm{x}=1.5$ and $\mathrm{L} 1$ at $\mathrm{x}=1.5 \mathrm{~m}, \mathrm{y}=0.8$

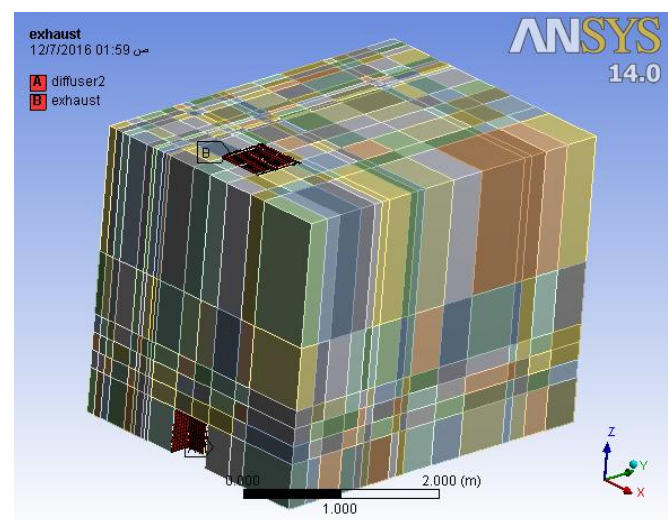

Fig. 10 Meshed model (Type-I)

The number of nodes and type of elements of cells for the three types and depending on many testing meshes were : 701528,Hex8,126095,Hex8 \&Wed6 and 719446,Hex8\&wed6, respectively. Fig.10 shows the meshed model for modeled room.

When solving problem numerically it's impossible to get an exact solution, so an accepted scaled error residuals should be specified for different terms such as continuity, velocity components and energy.

Excessive unwanted air movement makes occupants complains because of undesired cooling of some human body parts caused by this air movement 'draft'. For this reason, values of the air speed should be also controlled in design criteria to maintain good index of thermal comfort. Values of air speed are used to find the effective draft temperature (EDT), which is essential to predict the air diffusion (distribution) performance index (ADPI). This parameter is helpful in assessment of 
diffusion performance of air for diffusers in a ventilated space. The effective draft temperature (EDT) is calculated from equation below [5]:

$\mathrm{EDT}=(\mathrm{Tx}-\mathrm{Tav})-8 *(\mathrm{Vx}-0.15)$

The air diffusion (distribution) performance index (ADPI) is a percentage that is defined by the number of points measured in an occupied zone where EDT is within the set limit $\left(>-1.7^{\circ} \mathrm{C}\right.$ and $\left\langle 1.1^{\circ} \mathrm{C}\right.$ ) over the total number of points measured in it, [4].

Effectiveness temperature, another parameter in the present study is used to Confirm the results that obtained from (ADPI). The effectiveness temperature is calculated by using the following equation :

$$
\varepsilon_{-} \mathrm{t}=\left(\mathrm{T} \_\mathrm{o}-\mathrm{T} \_\mathrm{i}\right) /\left(\mathrm{T} \_\mathrm{m}-\mathrm{T} \_\mathrm{i}\right)
$$

Where,

$\varepsilon_{\mathrm{t}}=$ Effectiveness temperature

$\mathrm{T}_{\mathrm{o}}=$ temperature at return grille

$\mathrm{T}_{\mathrm{i}}=$ temperature at supply air diffuser

$\mathrm{T}_{\mathrm{m}}=$ temperature at occupied zone in tested room

\section{3 Verification Case}

The validation was done by comparing the realizable $k-\varepsilon$ model results with experimental data obtained in an office room with a wall-supply displacement ventilation system[12]. The comparison included:

1) Mesh strategy: Fig.11 observes the convergence in mesh distribution between present simulation result and Ref.[12]

2) Temperature contour : Fig.12 observed the similarity in temperature distribution at region before the obstacle between the present work and results obtained from Ref[12] , since there is a difference in the thermal gradient after obstacle. Where observed thermal gradient at the obstacle and at $t$ he region nearby return grille

3) Stream line: Fig.13 shows the main air stream moves toward obstacle and then moves to return air grille. This flow drives the air in region that not subjected to it directly and causing eddies .These regions are above the supply grille and behind obstacle .The comparison between present results and results obtained from Ref.[12].

4) Temperature distribution: The comparison which used between the data obtained from Ref.[12] , at distance $(X=0.5 \mathrm{~m})$ as shown in Fig.14,with the observed results from table 8 presents a validation gives a good agreement between the experimental data and the present results simulated by used the realizable $(\mathrm{k}-\varepsilon)$ turbulence model. Also, the percentage error not exceeded $(6.2 \%)$.

\section{RESULTS AND DISCUSSION}

From experimental results, Fig. 15 show the relation of air temperature versus the room height through poles 1,2 and 3. Since the temperature changes directly proportional with the room height. The temperature values increase with height due to increase of distance from air supply level.

Comparison between measured temperatures profiles at a pole od distance (0.8) $\mathrm{m}$ from air supply diffuser, with simulated temperature profile using realizable, $\mathrm{K}-\varepsilon$ turbulence model shown in Fig.16 for the three types of air supply diffusers.
The average deviation between the experimental and numerical values, for the three types were:6.8\%,4.04\% and $2.7 \%$ respectively.
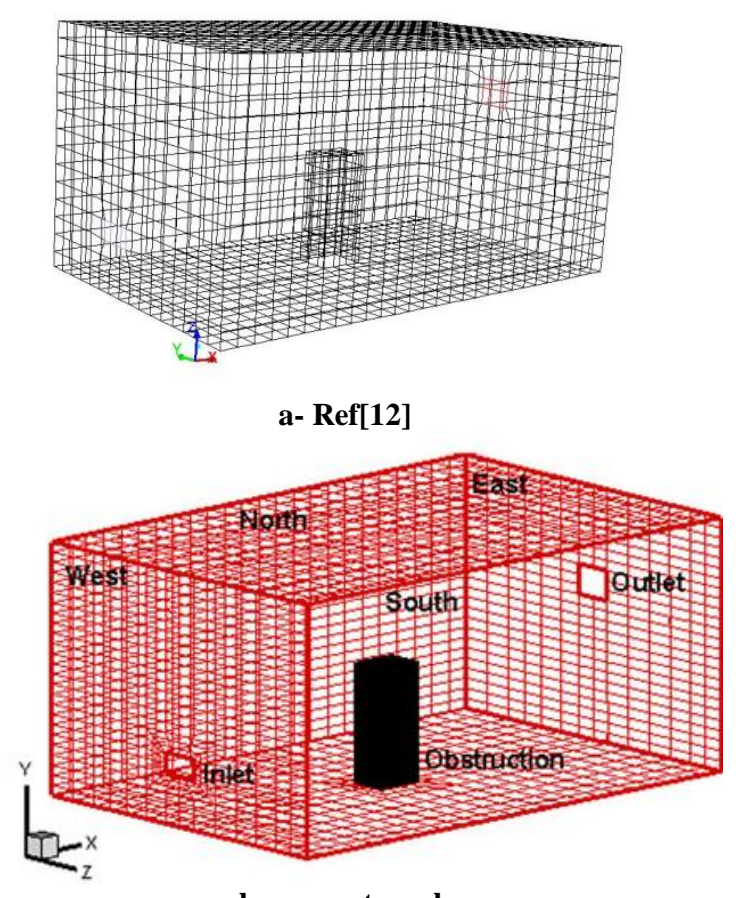

b- present work

Fig.11 Temperature distribution comparison between present simulation results and $\operatorname{Ref}[12]$

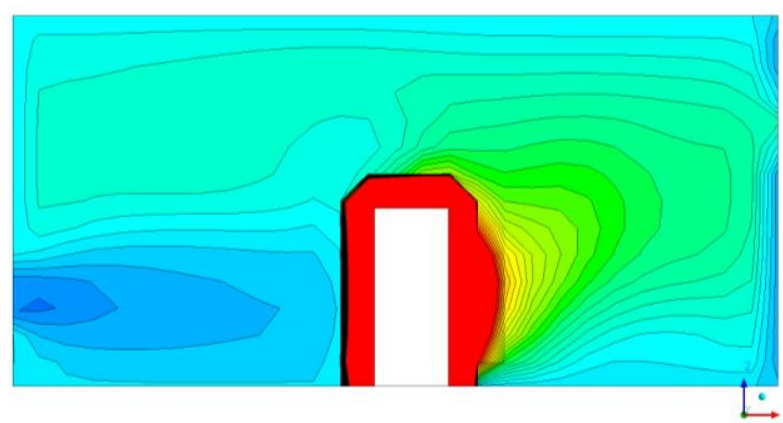

a- present work

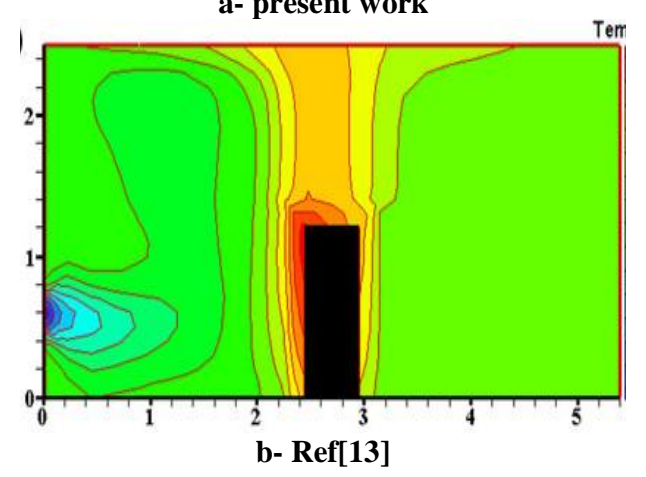

Fig.12 Temperature distribution comparison between present simulation results and $\operatorname{Ref}[12]$ 


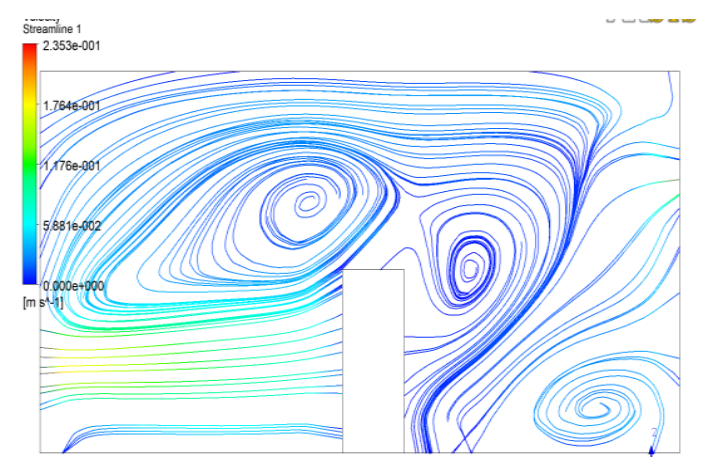

a- present work

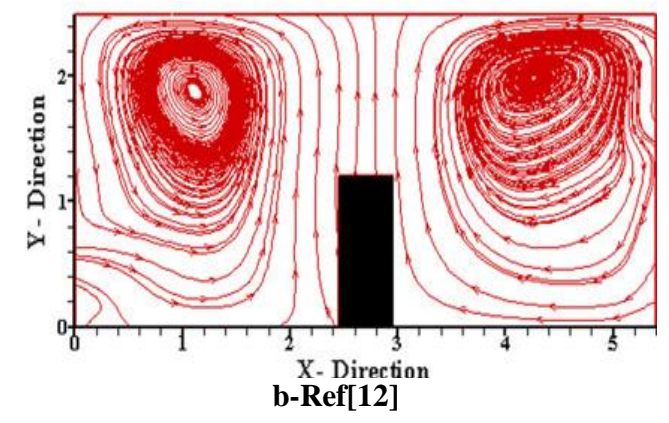

Fig.13 Temperature distribution comparison between present simulation results and Ref[12]

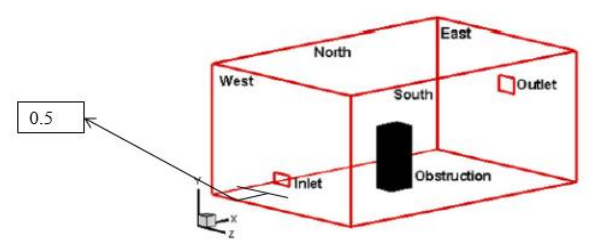

Fig.14 A geometry of temperature profiles for a

reference line at $(x=0.5 \mathrm{~m})$ used in Ref. [12]

Table 8 Temperature distribution comparison for the validation cases between the present work and Ref. [12]

\begin{tabular}{|c|c|c|c|c|}
\hline$Z_{m}$ & $\frac{t-t_{i}}{t_{z}-t_{i}}$ & $\boldsymbol{T}_{\operatorname{exp[12]}}$ & $\begin{array}{c}T_{C F} \\
\text { [present work] } \\
K \\
\end{array}$ & Error \% \\
\hline 0 & 3 & 314 & 297 & 5.4 \\
\hline 0.2 & 2.6 & 303.5 & 295.4 & 2.66 \\
\hline 0.5 & 1.5 & 317.5 & 299.274 & 5.7 \\
\hline 1 & 3.5 & 317.5 & 299.29 & 5.73 \\
\hline 1.5 & 3.5 & 316.5 & 299.14 & 5.36 \\
\hline 2 & 3.3 & 317.5 & 297.5 & 6.2 \\
\hline 2.5 & 3.5 & 311.2 & 298.87 & 3.9 \\
\hline
\end{tabular}

The numerical results in the present study for the tested room was adopted using many computational runs at various planes as illustrated in table 9and for all the domain . Air Distribution Performance Index (ADPI) was determined. All obtained variables were illustrated in the next sections for each diffuser type study.
Table 9 Locations of selected planes

\begin{tabular}{|c|c|c|}
\hline Plane No. & Plane & Location \\
& & $\boldsymbol{m}$ \\
\hline Plane 1 & $\mathrm{XZ}$ & $\mathrm{Y}=2$ \\
\hline Plane 2 & $\mathrm{XY}$ & $\mathrm{Z}=0.5$ \\
\hline Plane 3 & $\mathrm{XZ}$ & $\mathrm{Y}=3$ \\
\hline
\end{tabular}

\subsection{Comparison Between D.V Supply Air Diffusers:}

Accepted results can be obtained for all types when the return air grille located above the supply air diffuser at room false ceiling since it gives suitable thermal comfort in modeled room for the types of displacement ventilation devices (three direction-square diffuser, semi-circle diffuser and one direction-square diffuser). Numerically from K- $\varepsilon$ turbulence model, amongst the three types of diffusers gives:

Table 10 presents numerical results of Air Distribution Performance Index (ADPI).The maximum value of Air Distribution Performance Index (ADPI) founded at type-I that evaluated at two heights of breathing zones.

Table 10 Numerical values of ADPI,

\begin{tabular}{|c|c|c|c|}
\hline DV Type & Type-I & Type-II & Type-III \\
\hline $\begin{array}{l}\text { Level } \\
\text { 1.2(m) }\end{array}$ & 52.8 & 53.64 & 18.75 \\
\hline $\begin{array}{l}\text { Level } \\
\text { 1.6(m) }\end{array}$ & 66.67 & 62.375 & 35.4167 \\
\hline
\end{tabular}

From calculations for effectiveness temperature $\left(\varepsilon_{t}\right)$, the comparison between the three types showed that maximum effective temperature is satisfy clearly, at (type-I)then(typeII)and lowest value occurs at (type-III) as listed in table 11 .

Iso-surface temperature at $19^{\circ} \mathrm{C}$ shown in Fig.17, the cold air spreads through the floor of the room from the inlet close to the floor level where the maximum velocity was found out. It show that at type-I generally have the lower temperature spreading than others two types.

Iso-surface temperature at $22{ }^{\circ} \mathrm{C}$ represented in Fig18.The spreads at this temperature was same in type-II, and type I while was differ than type-III. Also, it can be seen the same spreading behaves at $24{ }^{\circ} \mathrm{C}$ in types II and I, while was less in type-III , as shown in Fig. 19.Then at $26^{\circ} \mathrm{C}$ as shown in Fig.20.

Table 11 Numerical values of effectiveness temperature

\begin{tabular}{|c|c|}
\hline Type & Effectiveness \\
\hline type-I & 1.823 \\
\hline type-II & 1.552 \\
\hline type-III & 0.173 \\
\hline
\end{tabular}

At type-I, spreading occurred better than the others two types. According to numerical results .Iso-surface temperature at $30{ }^{\circ} \mathrm{C}$ for the three displacement ventilation air supply diffusers, as represented in Fig.21. Spreading at type-I in this temperature accumulated only at smallest zone at southern region. So that allows staying the occupied zone in thermal comfort. However, in other two types, type-II and type-III, the hot region spreading wider. 
Lastly, iso-surface temperature at $37{ }^{\circ} \mathrm{C}$ and as represented in Fig. 22.Also, spreading at type-I in this temperature accumulated only at smallest zone at southern region. Therefore, that allows staying the occupied zone in thermal comfort. However, in other two types, type-II and type-III, the hot region spreading wider.

Numerically, Fig. 23 presents streamlines flow patterns entered to room from diffuser of three directions. The main face directed to the northern wall and slightly raise towards the return grille, while from each of the other two side faces streams moves toward and impinges its opposite wall and then turns toward northern wall. This process causes some small eddies near opposite corner and then these streams moves in similar path of the main stream towards return air grille. The movement of air caused by buoyancy and inertia forces.

In semi-circle air supply diffuser results shown in Fig.24.Air enters to all parts at room from semi-circle diffuser uniformly, radially and then rises. This was due to both pressure and buoyancy affect. The uniform air supplying in all room directions leads to minimum of eddies comparing to other types and consequently minimum flow turbulence. Also, uniformly flowing air causes a more uniform heat extraction from room space, which improves thermal comfort within room.

It one direction-square diffuser by using two corner units, streamlines flow patterns shown in Fig.25.Air enters room from each supply grill horizontally over the floor at angle $45^{\circ}$ in corners. These two streams move until meet and forming a single main stream, that directed towards northern wall. Where this main stream reaches, northern wall it moves upward to return grill driven by both pressure and buoyancy forces.

Fig.26 shows the induced noise level at minimum value in type-I, and maximum value in type-III. Random fluctuations in fluid motion are proportional to turbulent kinetic energy of fluid. Since these fluctuations are one of the main causes of induced noise by air motion. So range of values of kinetic energy gives an indication of noise level.

\section{CONCLUSIONS}

Experimental and numerical investigation on airflow and temperature distribution under different geometries of displacement ventilation devices in an office room were carried out to assess the performance of thermal human comfort and indoor air quality under Iraqi climate. From the results of the present study, the following conclusions can be summarized as follow:

1) The comparison between the three devices at the same supply air temperatures (19 and $\left.20{ }^{\circ} \mathrm{C}\right)$ with supply air velocity $(0.24$ and $0.25 \mathrm{~m} / \mathrm{s})$ found that the three direction-square air supply diffuser was the suitable type amongst the three type according to the human thermal comfort and indoor air quality under Iraqi climate .

2) From the results comparisons, the values of (ADPI) were calculated to all cases. The maximum value was (66.675) at type-I, while the minimum value was (35.23) and it found from type-III..

3) From the comparison for $\left(\varepsilon_{t}\right)$, the maximum value was (1.824) and obtained from type-I while the minimum value was (0.173)and found from type-III.

\section{NOMENCALTURE}

$A_{f}=$ the floor area of room $\left(\mathrm{m}^{2}\right)$ $\mathrm{c}_{\mathrm{p}}=$ specific heat of the air at constant pressure, [kJ/kg.K].

$\mathrm{q}_{\mathrm{oe}}=$ low level internal heat sources load, $(\mathrm{W})$

$\mathrm{q}_{\mathrm{l}}=$ ceiling lighting heat source load, $(\mathrm{W})$

$\mathrm{q}_{\mathrm{ex}}=$ Heat gain from external environment through walls,

$q_{t}=$ total heat transfer rate, $(\mathrm{W})$

$\mathrm{T}=$ Temperature $\left({ }^{\circ} \mathrm{C}\right)$

$\mathrm{T}_{\mathrm{x}}$ : local temperature $(\mathrm{K})$

$\mathrm{T}_{\mathrm{av}}$ : average room temperature $(\mathrm{K})$

$\mathrm{V}_{\mathrm{x}}$ : local air velocity $(\mathrm{m} / \mathrm{s})$

$t_{s p}=$ setup temperature, $\left({ }^{\circ} \mathrm{C}\right)$

$\rho=$ density of air, $\left[\mathrm{kg} / \mathrm{m}^{3}\right]$
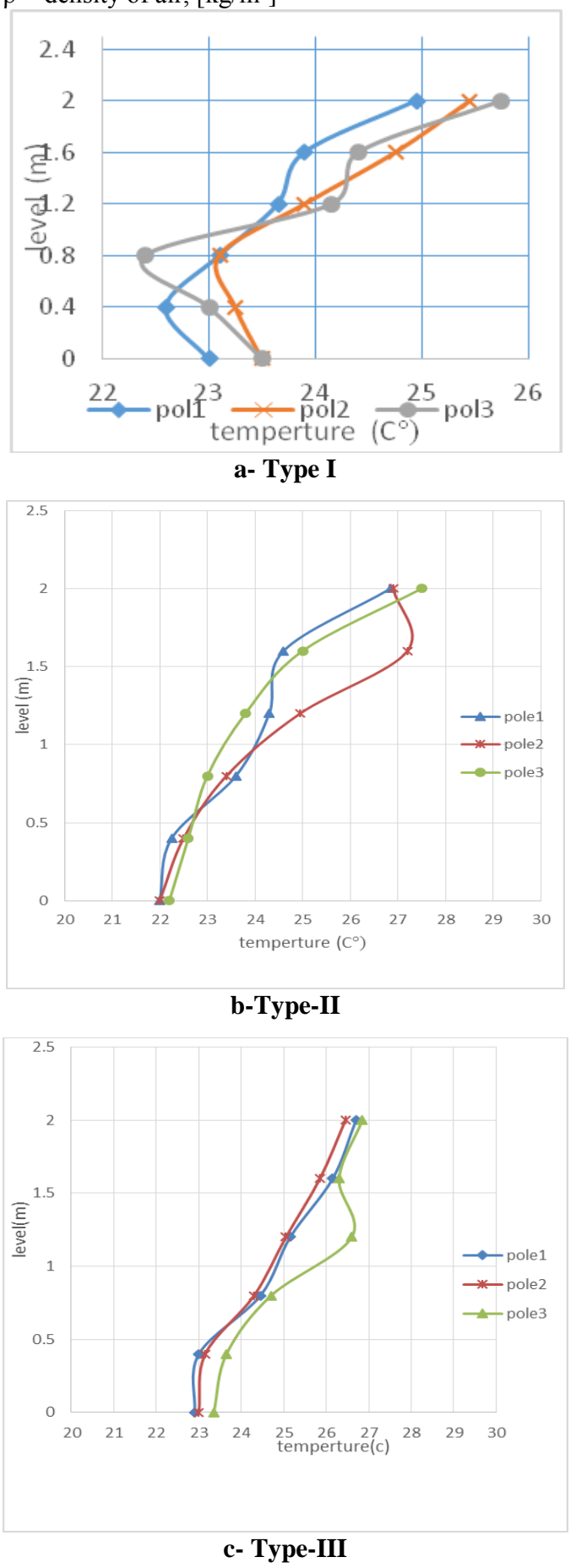

Fig.15 Measured temperature distributions from poles1,2and 3 


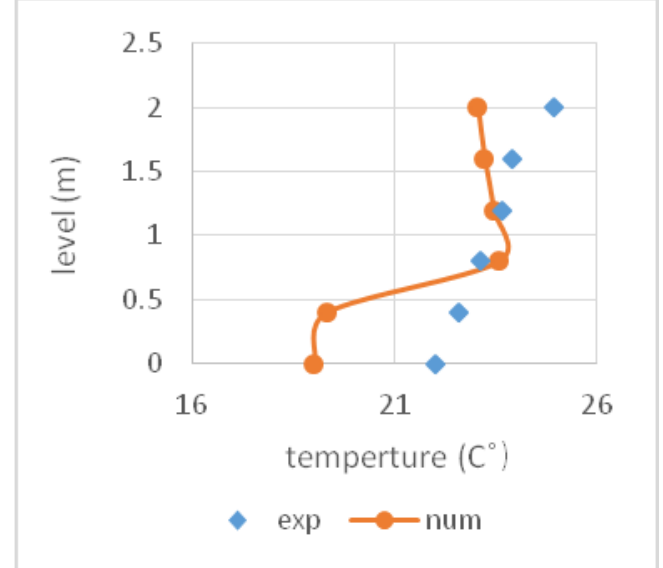

a- Type I
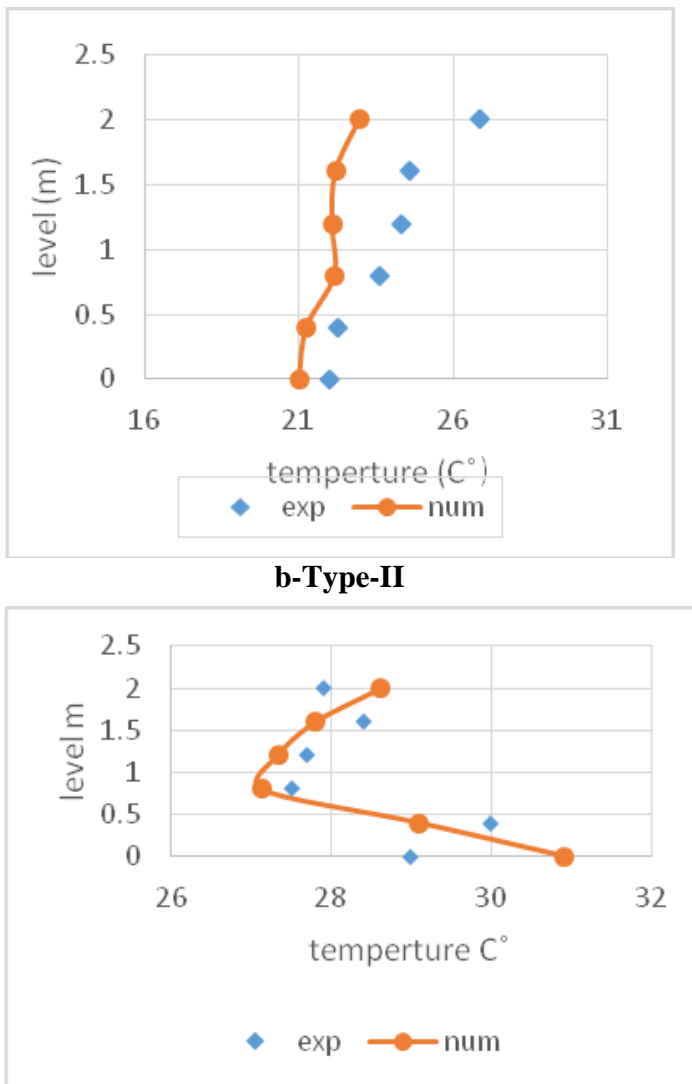

c- Type-III

Fig.16 Comparison between predicted and experimental results at pole 1 for three types of supply diffusers

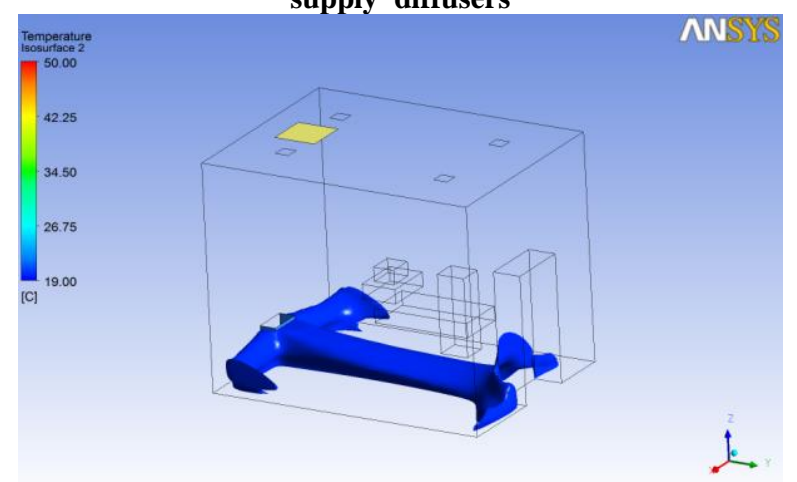

a- Type I

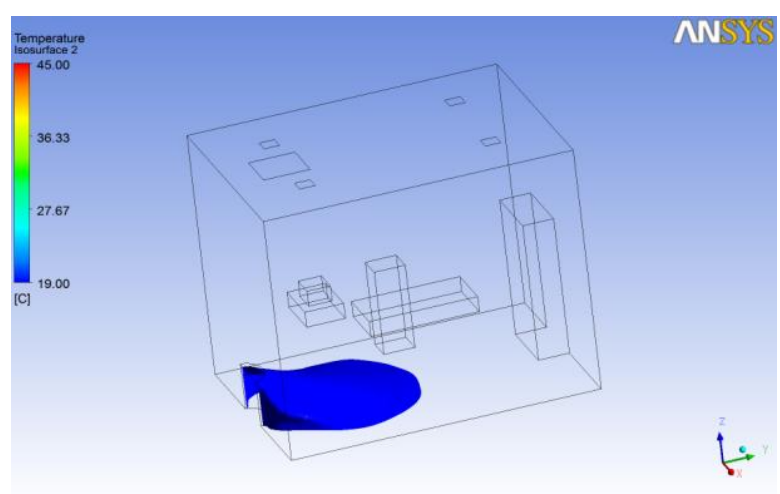

b-Type-II

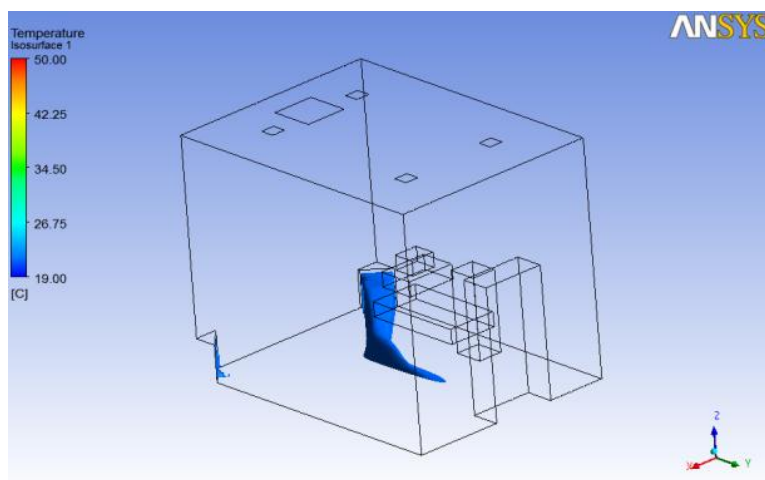

c- Type-III

Fig.17 Computed isosurface temperature at $19{ }^{\circ} \mathrm{C}$

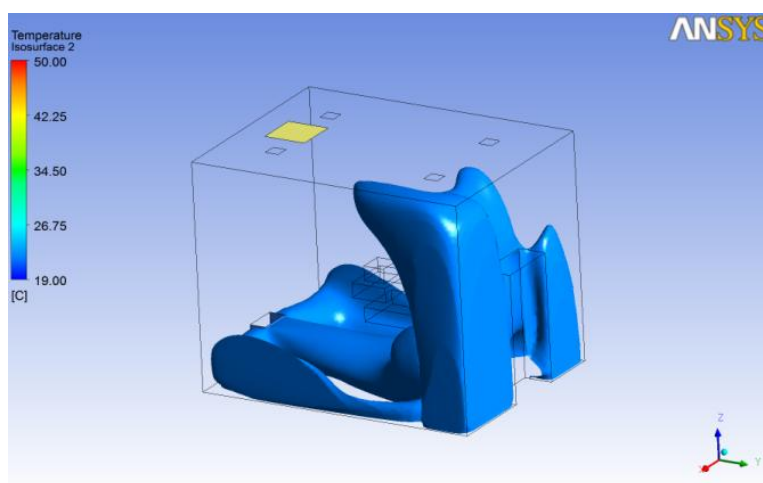

a- Type I

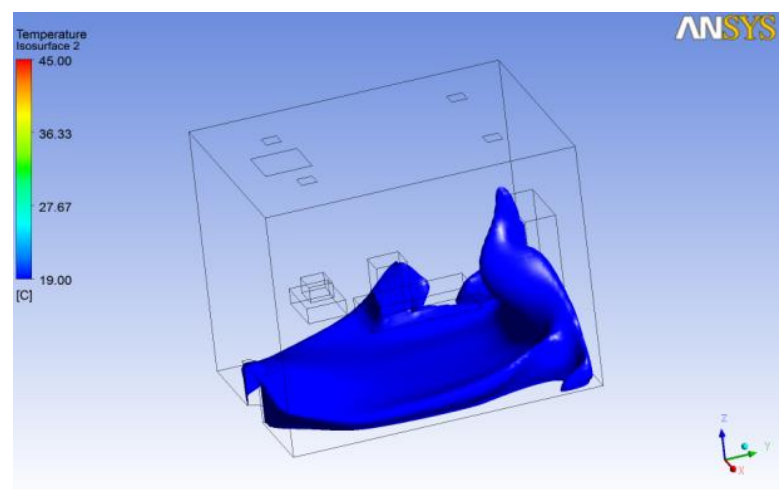

b-Type-II 


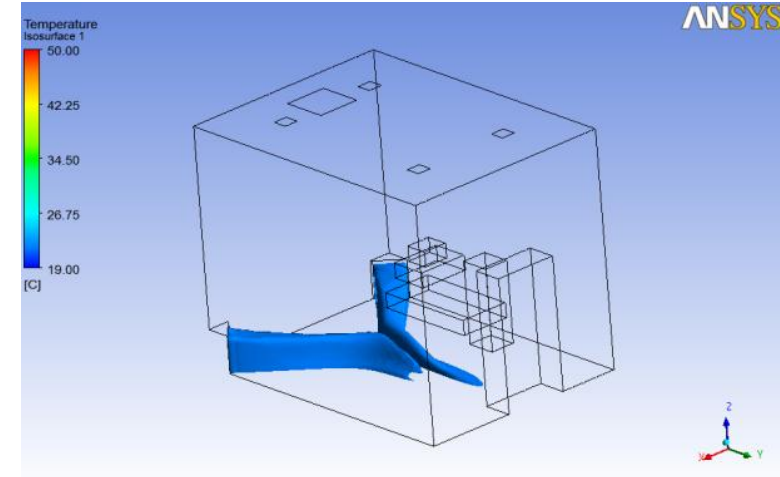

c- Type-III

Fig.18Computed isosurface temperature at $22^{\circ} \mathrm{C}$

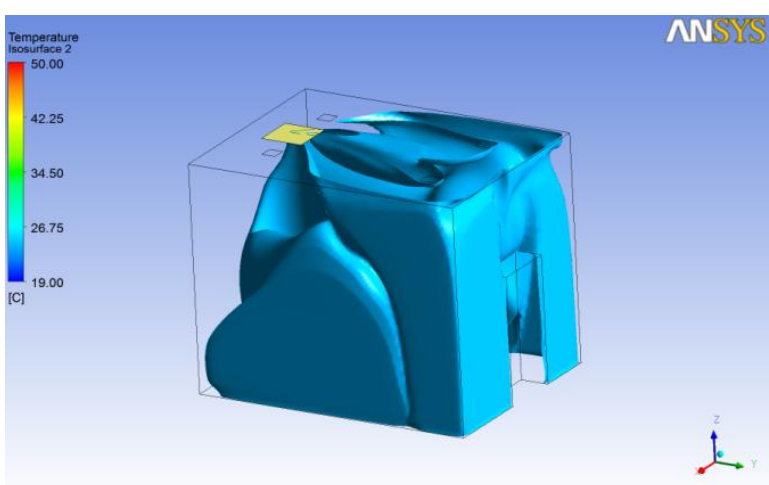

a- Type I

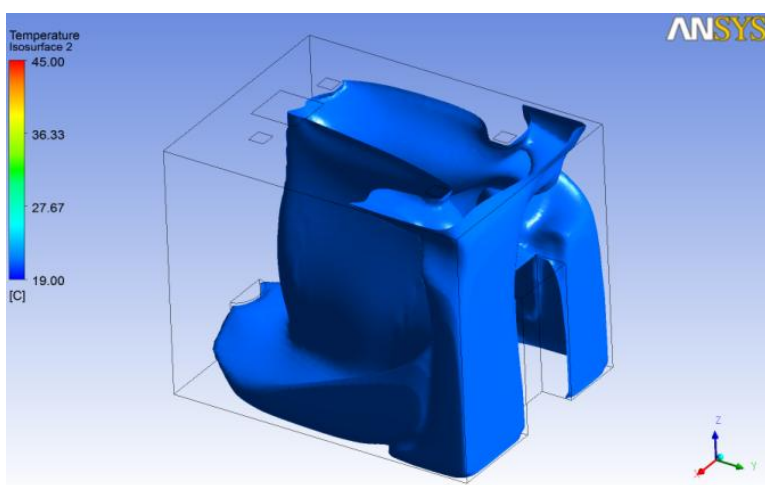

Type-II

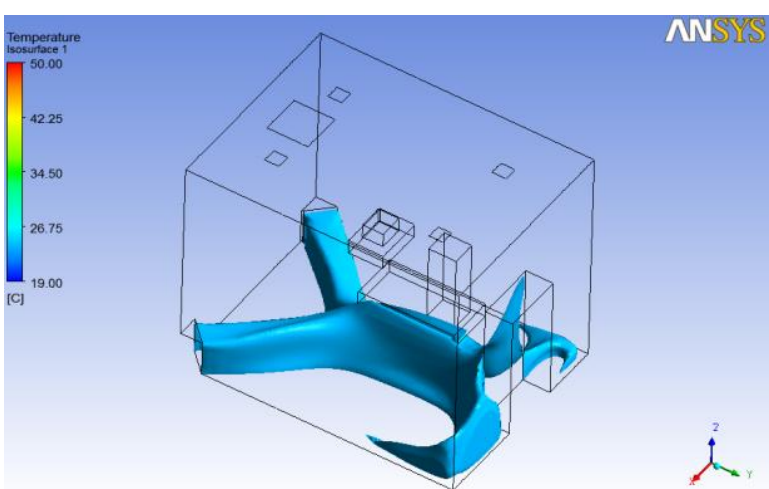

Type-III

Fig.19 Compute isosurface temperature at $24^{\circ} \mathrm{C}$

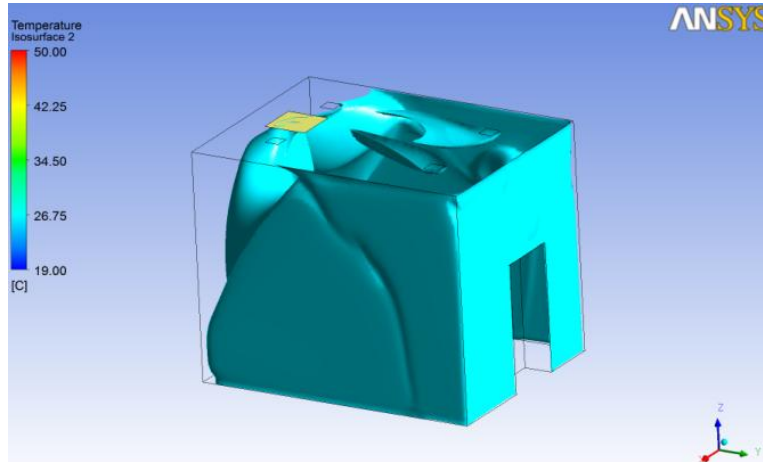

a- Type I

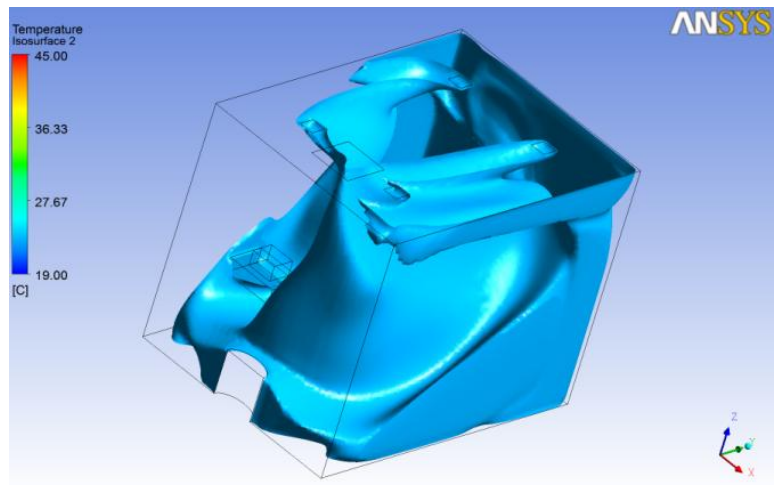

Type-II

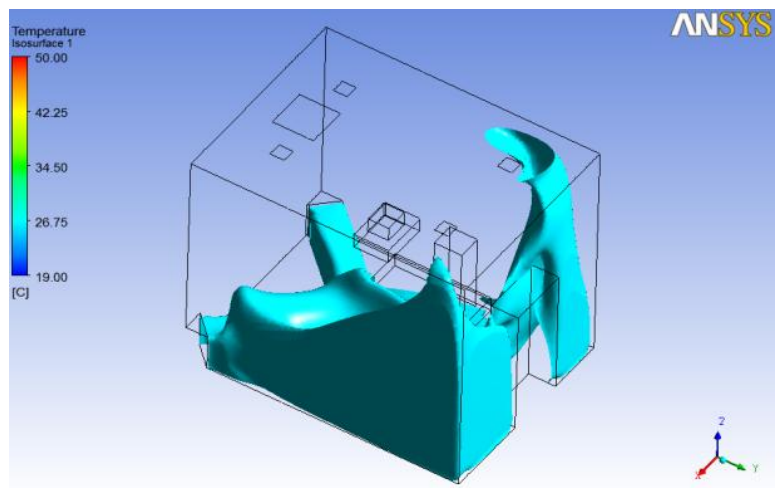

Type-III

Fig.20 Computed isosurface temperature at $26^{\circ} \mathrm{C}$

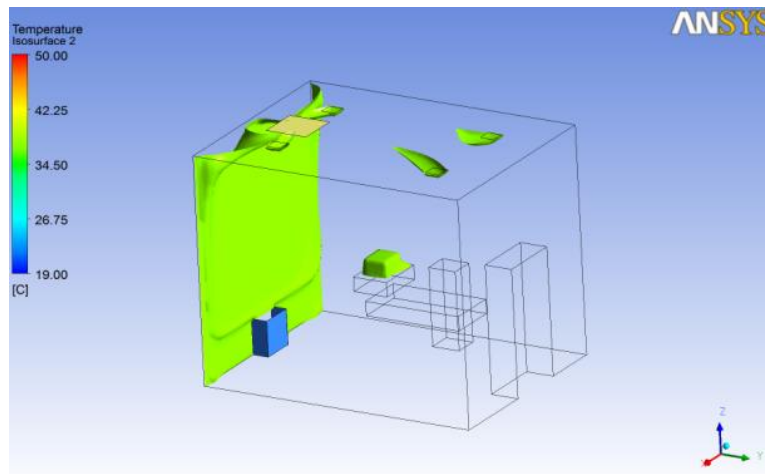

a- Type I 


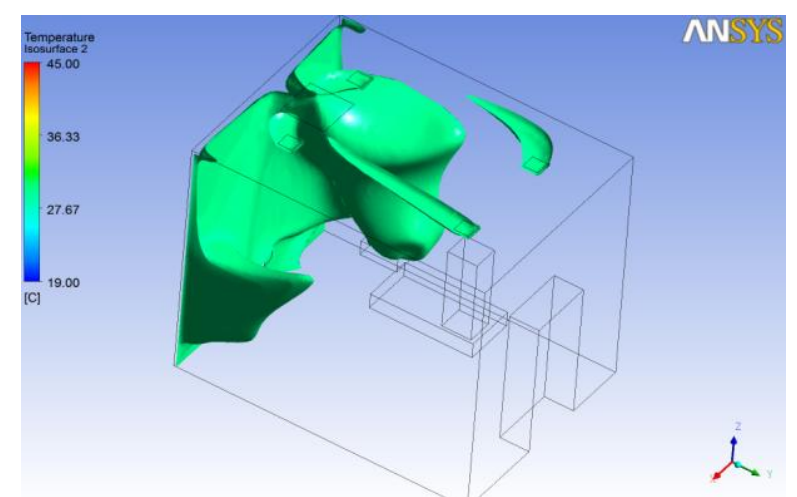

Type-II

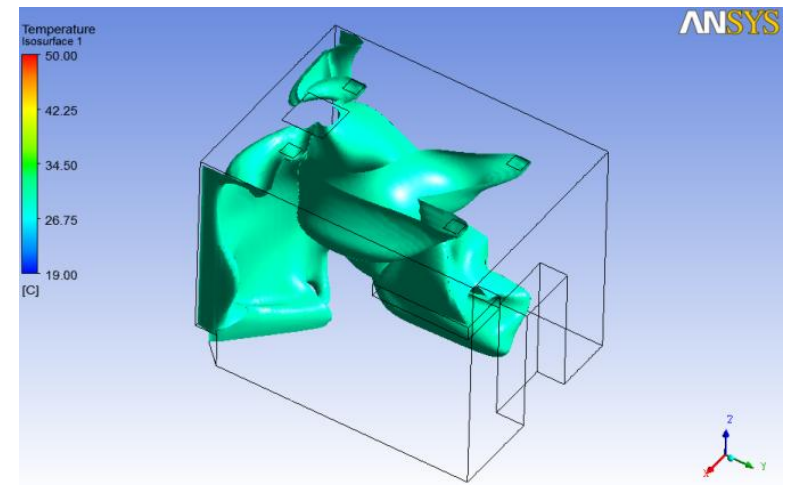

c- Type-III

Fig.21Computed isosurface temperature at $30^{\circ} \mathrm{C}$

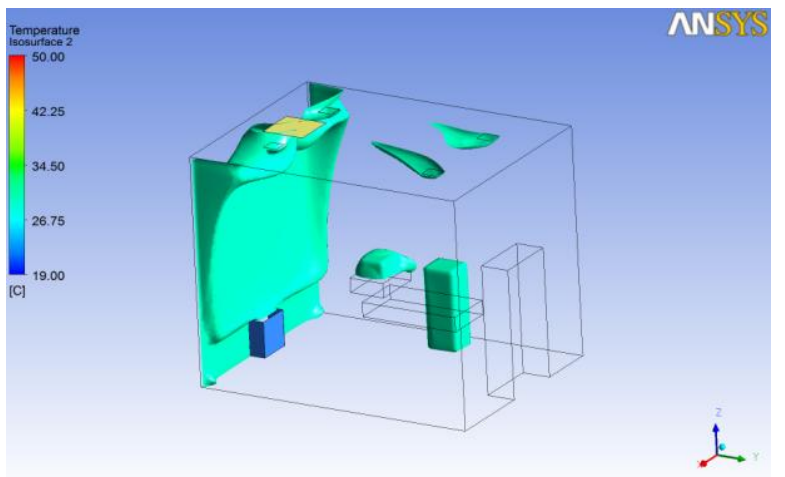

a- Type I

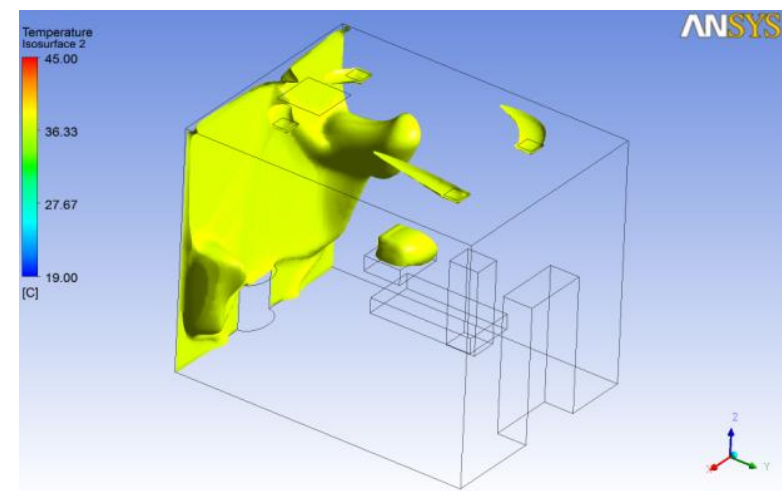

Type-II

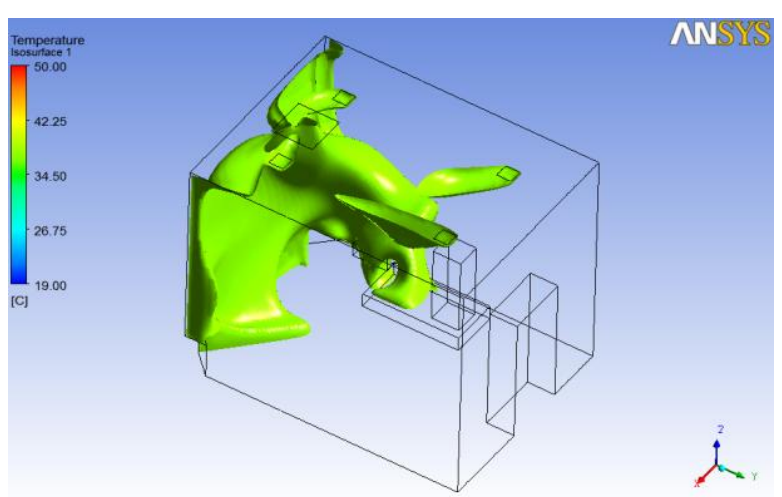

c- Type-III

Fig.22Computed isosurface temperature at $37^{\circ} \mathrm{C}$

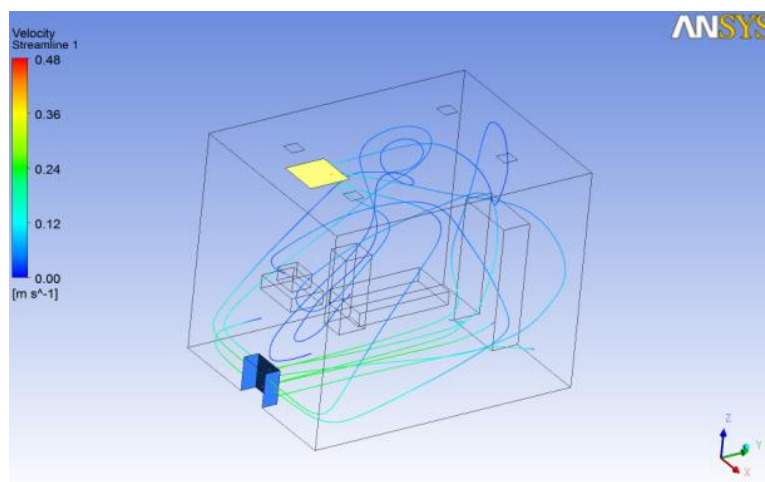

Fig.23 Computed stream lines flow pattarn, type-I

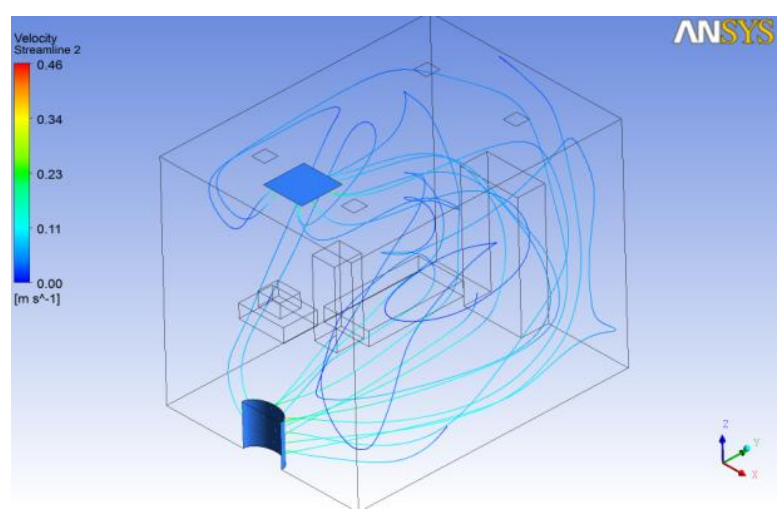

Fig.24Computed stream lines flow patterns, type-II

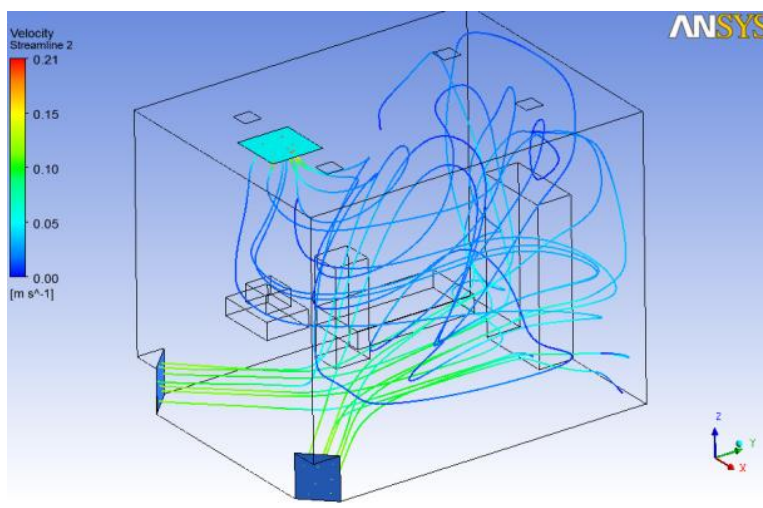

Fig.25 Computed Stream lines flow patterns, type-III 


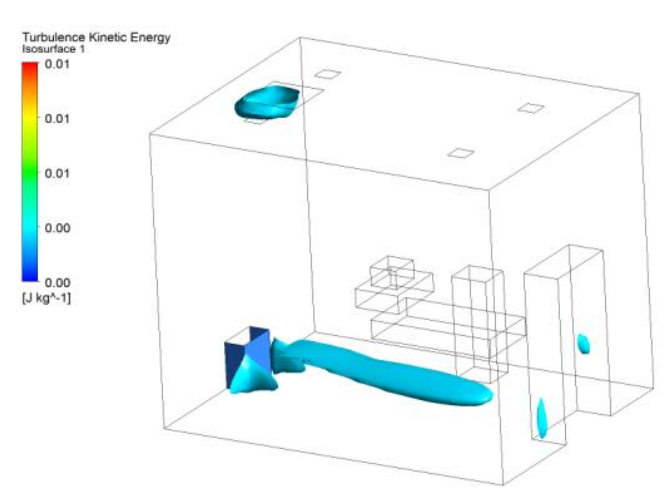

a-Type I

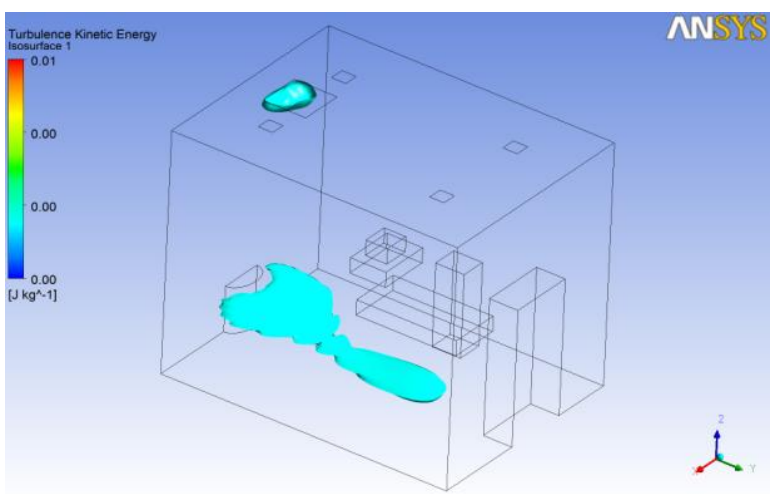

b-Type-II

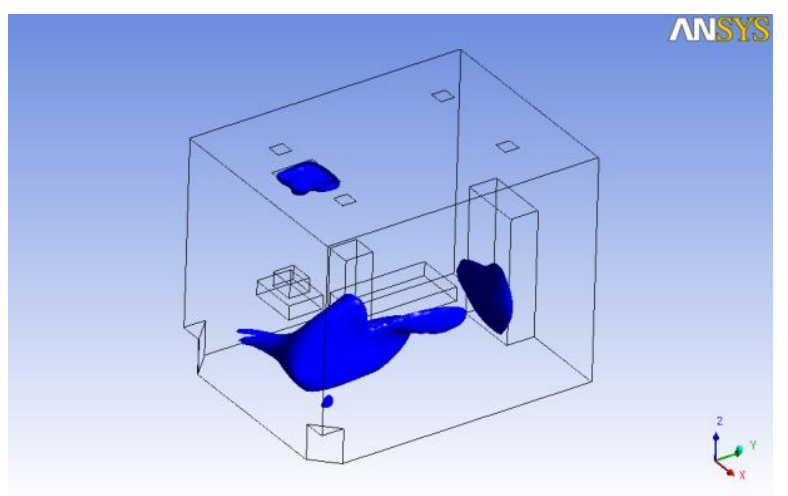

c- Type-III

Fig.26Turbulence kinetic energy

\section{REFERENCES}

[1] H.B. Awbi Measurement and calculation of the neutral height in a room with displacement ventilation, Building and Environment 37, A Department of Engineering Science, University of Oxford, Oxford, UK 2002Heywood J. Internal combustion engine fundamentals. McGraw-Hill, 1988.

[2] T.K.Arimipanahi, The air distribution index as an indication of consuming Energy and ventilation systems performance, Journal of the Human-Environmental System .Vol. 11; No. 2: 77-84, 2008.

[3] Ting Yao, Numerical Study Of The Effect Of Air Terminal Layouts On The Performance Of Stratum Ventilation System, International High Performance Buildings, Conference School of Mechanical Engineering,2014.

[4] Yukihiro Hashimoto, Numerical investigation on airflow in an office room with a displacement ventilation system, Ninth International IBPSA Conference ,Montréal, Canada, August 15-18, 2005.

[5] isup Lee, Comparison of airflow and pollutant distributions in rooms with traditional displacement ventilation and under-floor air distribution systems, ASHRAE Transactions, 2009.

[6] Price engineer's HVAC Handbook, "Engineering guide displacement ventilation, www.price-hvac.com, 2014.

[7] Brohus, H. "Personal exposure to contaminant sources in ventilated rooms",PhD thesis, Aalborg,University, Aalborg, Denmark. 1997.

[8] Chen, Q. \& Glicksman, L. "system performance evaluation and design guidelines for displacement ventilation", ASHRAE, Atlanta,PP:112,2003.

[9] Qasim H. ,Numerical Study of Air Velocity and Temperature Distribution by Displacement Ventilation,M.SC ,thesis, 2014

[10] H.B. Awbi, "Ventilation of Buildings", Taylor and Francis group, second edition,2003.

[11] Abdul-Jabar M. Ahmed, "Regional Airflow Characteristics in Mechanically Ventilated Rooms", M.Sc. Thesis, University of Technology, 2004.

[12] M.Cehlin, Measurements of air temperatures close to a low-velocity diffuser in displacement ventilation using an infrared camera, Energy and Buildings 34,2002. 